\title{
Una voz político-literaria para el letrado a las puertas de la Edad Moderna
}

\section{A Political-literary voice for the letrado in the Early Modernity}

\section{Pedro M. Cátedra}

https://orcid.org/0000-0001-6343-3530

IEMYRhd, Universidad de Salamanca

ESPAÑA

catedra@usal.es

[Hipogrifo, (issn: 2328-1308), 9.2, 2021, pp. 15-28]

Recibido: 17-02-2021 / Aceptado: 13-04-2021

DOI: http://dx.doi.org/10.13035/H.2021.09.02.03

Resumen. A finales de la Edad Media, abundan ejemplos de textos literarios menores, con contenido y fines administrativos, políticos o protocolarios, que medran en el ámbito de la nueva burocracia que se consolida en la Península Ibérica durante el reinado de Isabel I de Castilla y de su marido Fernando II de Aragón. Modelos administrativos de la llamada literatura gris y géneros retóricos no fueron solo muestras de la supervivencia de una cultura curial, o de ephemera socioliterarios, sino también instrumentos de los funcionarios del Estado, al servicio de la Corona, y de sus prácticas textuales. En este artículo se presta atención a una de esas muestras que, sin dejar de ser resultado de modelos retóricos tradicionales, testimonia la posible emergencia de algún concepto político esencial en la renovación de la monarquía durante la Edad Moderna.

Palabras clave. Retórica y política; literatura funcionarial.

Abstract. At the end of the Middle Ages, there are many examples of minor literary texts, with administrative, political or protocol content and purposes, within the new bureaucracy that was consolidated in the Iberian Peninsula during the reign of Isabel I de Castilla and her husband Fernando II of Aragon. Administrative models of the so-called gray literature and rhetorical genres were not only samples of the survival of a curial culture, or of socio-literary ephemera, but also instruments of State officials, at the service of the Crown, and of their textual practices. This article 
pays attention to one of those samples that, while still being the result of traditional rhetorical models, testifies to the possible emergence of some essential political concept in the renewal of the monarchy during the Modern Age.

Keywords. Rhetoric and politics, Literature funcionarial.

Mirando hacia atrás, en muchos de mis libros y artículos he ido concretando, con la apariencia de un estudio de los textos a partir de sus contextos - universitario, cortesano-amoroso, religioso, político o administrativo - lo que considero uno de los fundamentos de mi trabajo, la atención al uso de la literatura tanto como al análisis interno de la propia literatura, sin olvidar nunca los desplazamientos hermenéuticos gracias a los cuales esta cambia de funciones y sobrevive (también aquí la renovación y reutilización es supervivencia).

Uno de los campos que me han interesado desde hace tiempo es lo que he dado en Ilamar la literatura funcionarial. Me gustaría depurar tal marbete de su aspecto más grisáceo o más marcado en la historia entendida en términos generales: en el ámbito de los estudiosos de la teoría y la práctica política en ámbitos como el italiano de los siglos XII-XIV se ha estudiado el corpus textual del poder (podestà) ciudadano, en esencia lo relacionado con la preparación práctica o guías para los pretendientes a desempeñar cargos de gobierno o una actividad curial, muchas veces inseparables, en los que, similarmente a los regimientos de príncipes, se facilitan instrucciones, modelos de comportamiento y gestión política, con, incluso, materiales específicos. Recordemos, por citar un solo ejemplo, Die Podestaliteratur Italiens im 12. und 13. Jahrhundert de Herter (1910), en donde este publica algunos textos de ese repertorio, que no solo son de consejo, sino también constituyen instrumentos mediadores, como ciertos manuales para la materialización escrita, con un protocolo, de la burocracia administrativa de los regímenes comunitarios, verbigracia un ars dictandi? .

Mi planteamiento y ámbito cronológico, sin embargo, sobre lo que llamo literatura funcionarial es distinto del que se requería en la gran época de Kantorowicz. Sin renunciar, obviamente, al estudio de la apropiación y uso de ciertos géneros retóricos por parte de una nueva personalidad o clase administrativa, me interesa más el proceso de "dinamización" - discúlpeseme el palabro-y recuperación por parte de un funcionario letrado de tales y otros géneros, que se vale de la "literatura" no solo como un referente sino también como un instrumento de auto-representación, de intermediación, de negociación entre poderes políticos tradicionales y emergentes, y de consolidación de estos últimos². Antecedente en la España del siglo XV es sin

1. Ni que decir tiene que instrumentos mediáticos como los géneros retóricos de la Edad Media, empezando por el citado, cumplen las mismas funciones en otros ámbitos. Para esos mismos siglos, y sin salir de España, tenemos repertorios, de la circulación administrativa de estos géneros, empezando por supuesto con los del Prof. Charles Faulhaber, cuyos repertorios y ediciones de textos fundamentales, son un pilar esencial para el uso del ars dictandi en distintos medios curiales y eclesiásticos.

2. El libro de Gómez Bravo, 2013, es una aportación fundamental en el terreno que nos movemos. Téngase en cuenta también Deyermond, 2005. 
duda la persona de Enrique de Villena, descendiente directo de las familias reales castellanas y aragonesas, que somete su dedicación y producción literarias, que podrían haberse desarrollado en la misma línea de otros aristócratas letraheridos, a un deslizamiento hacia la función política como medio de auto-identificación y auto-representación, tras de un protagonismo social y político3.

El último tercio del siglo XV y primeros años del XVI es el período que nos interesa al hablar de literatura funcionarial o, si se quiere, de la literatura del letrado, y de su caracterización; o, por mejor decir, de algunos géneros literarios que se recuperan o renuevan con vectores o factores que los condicionan o les prestan una concreta función. El primer vector o factor es el topográfico, es decir, el lugar - geográfico o institucional, por ejemplo una ciudad concreta o una covachuela en una secretaría de estado- en el que ese texto se materializa con una concreta finalidad, por lo general de poca duración. El segundo vector, es el factor humano, un conglomerado de actividad y pasividad recíproca, merced a la dependencia y relación de autor o autores y destinatario o destinatarios, una suerte de network, por utilizar el término de Gómez-Bravo (2013). El tercer vector es el de la acción, pues estos textos en cierto modo solo existen o cumplen su función cuando esta se corona con su performance -acción es también actio- en el marco político o protocolario para el que están destinados.

El texto delegaría su literariedad u originalidad no tanto en el alarde retórico o poético, cuanto en el conglomerado de sus funciones. Por ello los géneros funcionariales están invariablemente encajonados en la tradición retórica y la voz individual suele delegarse en la colectiva o se centra en los destinatarios.

Del estudio desde este punto de vista numerosos textos menores del período señalado generarían un rico catálogo nada despreciable. En mi monografía citada publico y estudio, entre otras cosas, los textos de una miscelánea manuscrita a la que vengo prestando atención desde principios de siglo a esta parte, que ya está bien. Esta gavilla de textos es un excelente ejemplo que puede dar una idea, aquí necesariamente somera, de los tipos de piezas que formarían parte de ese catálogo, pues nos ilustra sobre el variado abanico genérico, y de su lectura se deduce la función de estos textos representativos de la cultura funcionarial del letrado en torno a los años de madurez de esta nobleza de toga que emerge y se consolida protagonista en y de la administración del estado entre 1474 y 1510.

Aunque en este trabajo solo publicaré uno de los textos abroquelándolo con unas notas interpretativas, me parece útil y hasta necesario para el lector, si alguno hubiere, disponer de un elenco de las menudencias contenidas en la miscelánea con un breve comentario, que con más detalle se puede ver en otros lugares4:

3. No es el lugar apropiado este para recordar el desplazamiento hermenéutico al que somete temas y géneros para intentar dotarlos de una capacidad de influencia política, a lo que me he referido con más detalle en trabajos que ahora no son del caso (véase, sin embargo, entre otros Cátedra, 2002a, 2002b y en prensa).

4. Véase Cátedra, 2009a. Algunos de estos textos se han publicado exentos, pero todos figurarán en mi volumen en prensa. 
[1] Memorial [a los Reyes] de Martín Fernández de Angulo en favor de los hijosdalgo de Córdoba y su nobleza.

[2] Una carta bien escripta de un letrado a un grande sobre la gratitud.

[3] Carta consolatoria buena.

[4]-[5] Proposiciones de cortes.

[6] Del doctor Angulo por ruego de Luis de Quintanilla y otros cavalleros de Medina.

[7] Oraçion que hizo el doctor Alcoçer en Segovia a la Reina doña Isabel, nuestra señora, en nonbre destos reinos quando fue sublimada y resçebida por reina dellos martes día de santa Luzía xiii dias de deziembre de LXXXIIII años.

[8] Sobre la herida del Rey nuestro señor de Alfonso Martínez de Angulo

[9] De Alfonso Martínez de Angulo sobre la misma materia.

[10] Respuesta de los Reyes.

[11] Oraçión hecha al emperador Maximiliano en nonbre del senado y pueblo veneçiano.

[12] Fragmento de consolatoria.

[13] Consideraçión que haze el honbre consygo mismo. ¿Quién me llama? ¿Qué es aquesto? ¿Quién so yo? ¿Quién me levantó de la tierra? [...]

[14] Confesyón. Yo pecador errado [...]»

[15] De un escudero a la muerte del marqués de Villafranca, fijo del conde de Benavente, que murió en Alcalá de una caída de unos corredores.

[16] Miçer Alonso de la Cavallería a la muerte del prínçipe don Johán.

[17] Fray Íñigo de Mendoça a la reina doña Isabel, n. s., sobre la muerte del prínçipe don Johán.

[18] Sobre la muerte del prínçipe don Joan de Alfonso Martínez de Angulo.

[19] Carta incompleta a los Reyes Católicos por Alonso Martínez de Angulo.

[20] Carta sobre la muerte del prínçipe don Johán al Rey y a la Reyna, nuestros señores.

Figuran ahí piezas que sirven a la construcción o mantenimiento de una nueva realidad política, que se materializan en forma de discurso oratorio (núms. 4, 5, 7 y 11). Son, sustancialmente, proposiciones a cortes por parte de letrados -las de los Reyes también las solían escribir estos - ; discursos para la legitimación de un cambio político, como la Oración de Díaz de Alcocer (7), que pasarán a preservarse en la historia oficial ${ }^{5}$; orationes con una finalidad propagandística o de manipulación histórica como las que subyacen en la oración falsamente pronunciada núm. 11; o discursos destinados a una lectura pública providencialista de la historia presente para rescribirla en una nueva dirección, como los referidos a la herida del Rey o al atentado de Barcelona contra Fernando el Católico en 1492 (8, 9 y 10). De cada una de estas piezas, como de la siguientes, podemos encontrar modelos clásicos.

En segundo lugar, figuran textos representativos de la retórica de la vida pública, que sustenta y da soporte escrito a las nuevas bases de la relación política, como, por ejemplo, la emergencia de la vox populi por medio de la interpelación escrita u oral al poder ( 1 y 6); o la nueva redefinición del concepto de gracia, como veremos.

5. Publiqué texto y estudio de la Oración de Díaz de Alcocer en Cátedra, 2009b. La principal especialista en la materia de la legitimación de Isabel la Católica, la profesora Carrasco Manchado, tuvo a bien juzgar mi trabajo e interpretación del texto, con conclusiones importantes a las que me referiré en mi libro en prensa. 
Y, en tercer lugar, figuran textos protocolarios en lo individual y en lo colectivo, que canalizan, a pesar de su banalidad o su función de mera etiqueta, las relaciones personales hieratizadas con el poder divino o el poder laico, así como también entre iguales. Por ejemplo, lo que he dado en llamar la retórica del fin, en torno al uso político de la muerte, con documentos aparentemente hológrafos de la última voluntad (13 y 14); la epístola u oración consolatoria como documento político o diplomático, y el propio rechazo del consuelo $(3,12,15-18$ y 20$)$.

Este manuscrito, BNE 19.365, agavilla piezas anónimas y otras atribuidas a funcionarios castellanos y aragoneses de primera y segunda línea. Temas, contenidos y formas no se pueden desvincular de quienes son al tiempo sus autores y actores; antes, al contrario, el perfil de estos permite cohesionar todas estas manifestaciones como propias de un tronco común y, si se puede decir, de un estamento, integrado por personas, cuya relevancia política es, a día de hoy, inversamente proporcional al conocimiento que de su obra "literaria", por así decirlo, tenemos. En nuestra miscelánea figuran: Alfonso de la Cavallería, Juan Díaz de Alcocer, Martín Fernández de Angulo, Alfonso Martínez de Angulo, Íñigo de Mendoza, que formaban parte de ese grupo de colaboradores, consejeros o burócratas «destacados - utilizo las palabras de Rábade Obradó- por su eficacia y eficiencia, por su talento y aptitudes», que acabaron por formar un «círculo áulico capaz de secundar a la perfección las iniciativas regias» ${ }^{6}$.

Los cambios de organización del reino que tuvieron lugar tanto en Castilla como en Aragón en el último cuarto del siglo Xv hicieron posible la consolidación de ese entorno de los Reyes por medio de la recreación o reforma de los Consejos, en los que la jerarquía eclesiástica y una nobleza moderna de toga, con preparación intelectual, en muchos casos universitaria, predomina sobre otros estamentos que, en la organización anterior del estado, tenían mayor importancia. Dos de los autores mencionados, Fernández de Angulo y La Caballería, tienen gran relevancia en el consejo de Aragón y de Castilla, respectivamente.

El estudio particular de los miembros de esa oligarquía de poder que son los consejeros de los Reyes Católicos ha sido reclamado por varios historiadores modernos, entre otras cosas porque nos facilitaría, aparte el mejor conocimiento de las estructuras y del funcionamiento del aparato administrativo y político de los Reyes, la comprensión de la participación de esa clase en algunos de los más importantes acontecimientos del reinado, lo que arrojaría mucha luz sobre el conjunto del grupo y sobre el mismo reinado. Pues si el estudio individual de estos integrantes de las nuevas «profesiones abiertas al talento» es esencial; lo es también poner de manifiesto cómo unos determinados géneros retóricos, cuya presencia en la literatura tout court iba decayendo, pasan a convertirse en una especie de instrumento para la gestión pública y privada del estado, para la etiqueta de la relación política, así como también para la configuración de una nueva expresión y teoría políticas. 
El texto con el que quiero ilustrar una de las anteriores facetas es el número 2 de la miscelánea que, pese a su aparente insignificancia semántica e intrascendencia retórica "progimnasmática", si se me permite otro palabro, es testimonio del uso de un concepto importante del pensamiento político.

Helo aquí tal como se puede leer en el manuscrito:

\section{UNA CARTA BIEN ESCRIPTA DE UN LETRADO A UN GRANDE SOBRE LA GRATITUD.}

[§1] Entre las otras muy convenientes y loables virtudes, muy magnífico señor, que en los generosos varones deve aver, ninguna me paresçe mayor, segúnd mi rudeza lo entiende, que es la gratitud, porque desta todas han alguna parte en prinçipio; y, así, por el contrario, el desagradesçimiento doquier que se halla es aborresçible a toda persona. Y porque a vuestra merced plugo que en escripto reçitase algunas palabras que de la abundançia de mi deseo vos fueron ofresçidas, puesto que la falta del saber gravemente ocupase la pluma, mas como al amor ninguna cosa es difíçil, $y$, allende desto, aviendo de la merced vuestra grand confiança que mi defecto supliría, deliberé de lo poner así en obra, tomando aquesta virtud ya dicha por fundamento de la mal ordenada y breve escriptura, que, a vuestra merced, besando las manos, suplico le plega resçebir.

[§2] Muchas y muy prinçipales razones son aquellas que me movieron a començar desta virtud, porque a vos es más devida que a otro, reconosçiendo los benefiçios que primeramente de Dios avéis resçebido y después de la Fortuna, si la ay, lo qual por el presente no niego ni afirmo. Ca vos, después de aver nasçido hombre, que es el mayor bien que en la naturaleza se halla, desçendéis de alta progenie, sois dotado de singular disposiçión y de seso y reposo asaz templado y perfecto quanto a vuestra edad y a mayor pertenesçe en el prinçipio de vuestra moçedad, tomando el ${ }^{[3 \mathrm{v}]}$ estado y cargo de vuestra casa en verdad no tan cresçido quanto vuestra sufiçiençia pudiera bastar. Avéis con aquel emprendido tan difíçiles y altas cosas quanto yo pienso que ninguno otro con más días y mayor cresçimiento de dignididad y riquesa las osara emprender. Pues cómo aquellas han sido governadas y regidas y con quántos trabajos mezclados con miedo no solamente a los nuestros naturales es visto, mas a los estranjeros por fama notorio.

[§3] Así que en todo la Fortuna vos ha sido favorable, librando vuestra persona de infinitas asechanças. Avéis avido en vuestras prosperidades y adversidades muy fieles parientes y amigos, los quales con sus personas y caudales en aquellas amigablemente vos han seguido. No les avéis remunerado los grandes cargos que dellos tenéis, pienso que por la importunidad del tiempo o por no averse ofresçido a vuestras manos con qué pudiesen ser satisfechos. Baste que, sin enbargo destas cabsas, por la piedad y bondad de nuestro Señor sin ninguna caída e vos avéis sostenido e sostenéis, subiendo en mayor estado e honor que ninguno de vuestros antepasados.

[§4] E por que tantos y tales benefiçios no los escurezca ingratitud con el nublado de olvidança, por vía que la próspera y alegre Fortuna se permute en obscura y contraria a vuestro estado con maneras ignotas que jamás le fallesçen, devéis, señor, escudaros della con el escudo de aquesta clara virtud. Primeramente, conosçiendo y gradesçiendo a nuestro Señor los bienes que d'Él avéis [4r] resçebido. Y 
deste agradesçimiento, si perfecto es, nasçerá que seáis dotado de todas las otras virtudes que son plazientes a Él. Y, así, con el resplandor de su graçia sin ningúnd mundano temor biviréis en continua feliçidad.

[§5] Y dexando lo que pertenesçe a Dios, así como Aquel donde todos los bienes proçeden, mucho somos obligados de reconosçer las buenas obras que de los hombres resçebimos, mayormente de aquellos que con amor y buena voluntad nos siguen. Y porque de los movimientos pasados se representan muchas novedades, conviene que nueva provisión deis en vuestros hechos. Y puesto que tan claro no exprese las cabsas, bien bastará a vuestra discreçión que las apunte. Quanto a lo primero, porque vuestra palabra sea avida por fe y los escandalosos no ayan lugar de sembrar çizañia, cuyo fructo pueden coger. Con verdad qualquier pacto o conveniençia que con este pueblo tengáis devéis mucho conservar y guardar, añadiendo a esto palabras sabrosas y dulçes, tales que de temor los aparte y a vuestro amor los inçite. Así mismo los efectos de justiçia, que a otro secreto fin no se enderesçen, mandaréis esecutar, porque el estado de los pueblos mediante aquella se sostiene y de otra guisa no se pueden largamente sofrir sin caída.

[§6] Y, dexando las cosas generales y brevemente viniendo a lo particular, el amor, paz y sosiego de vuestros parientes y amigos soliçitad con mucho estudio, porque el oro que en este fuego de vuestros trabajos avéis apurado por descuidamiento e negligençia, no se convierta en cobre. $Y$ antes ${ }^{[4 v]}$ presuponed de perder alguno, si fuera de la raya saliere, que no, por tener aquel, dar cabsa que la mayor parte se pierda. Y, allende desto, de los apurados apurando algunos que seáis çierto que están en los veinte e quatro quilates de vuestro serviçio, partí con ellos de lo que buenamente podréis, porque, a unos satisfaziendo, a los otros sobiréis en aquella misma ley, considerando que la çierta e manifiesta esperança los pueda afinar, no çesando por tanto de tener a los tales en aquel grado e amor que, segúnd sus méritos y aun segúnd el tiempo, les pertenesçe; que todos no pueden ser de una igualdad, porque en las obras han de ser así como los paresçeres, diferentes, pero de todos y de cada uno en su grado vos podéis aprovechar y servir, en espeçial si el acogimiento y buena voluntad usáis con la gente, pues las dádivas y mercedes, acatada vuestra facultad, no lo pueden llenamente suplir.

Así que un joven caballero ha alcanzado el éxito y reconocimiento social que sus antepasados no llegaron a tener, y ha sido ayudado y secundado por muchos fieles y parientes, a los que, sin embargo, aún no ha gratificado. Para evitar que sus hechos queden oscurecidos por la ingratitud, el autor de la escriptura intenta persuadirlo para que salde su deuda, y enumera una serie de acciones que han de ser puestas en práctica en lo general y en lo particular para el buen gobierno de sus súbditos y la convivencia con sus parientes. Lo abrupto del final es quizá indicio de que el texto esté incompleto, o, cuando menos, se echa en falta una conclusión formal y protocolaria.

Desde el punto de vista formal, se advierte ya en el §1, donde se agrupan tópicos narrativos como la causa o razón de ser del escrito, con los propios del exordio, como la falsa modestia, el ambiguo estatuto de la escriptura, que se desliza de la epístola a la oratio, sobre todo si tenemos en cuenta las circunstancias narradas sobre la génesis oral del texto y de la recepción coetánea. A propósito de esto último solo contamos con su contexto material, formando parte de una colección 
variada en cuanto a sus modelos retóricos se refiere como la descrita. Esta contiene además fragmentos en busca de estructuras donde insertarse, que confieren al manuscrito una condición de repertorio profesional de modelos. El autor de la rúbri$\mathrm{ca}$, con su mano distinta de la que escribe el texto, ambas de principios del siglo XVI, percibe en él elementos propios del arte epistolar y no duda en calificarla de carta.

Esta ambigüedad formal entre modelos retóricos es la que se aprecia también en otras piezas de la miscelánea. Pero en el caso que atendemos aquí parece que el deslizamiento es también "performativo", de lo oral a lo escrito y viceversa, lo que realza la funcionalidad. Se aprecia, por ejemplo, cuando, al declarar las causas de la escritura, el autor afirma que al engrandecido destinatario del texto «plugo que en escripto reçitase algunas palabras que de la abundançia de mi deseo vos fueron ofresçidas». Basta con acudir al CORDE de la Academia para comprobar que recitar se usaba en la Edad Media para definir tanto una práctica oral como escrita, con lo que se abarcan ambas prácticas que me parecen aludidas por el autor de nuestro texto: el deseo de recordar, más que de saber, del destinatario remonta a una comunicación/conversación oral entre quienes quizá tenían una relación más estrecha, quién sabe si desde el punto de vista educativo o de consejo, pues, entre otras cosas, el asunto que se ventila es también propio del ámbito de los regimientos de príncipes.

El tono de escritura formal, no obstante, depende de la condición de la misma y de su destino, de su poética (protocolaria o familiar), y de la relación de los correspondientes. En el ámbito retórico, sin embargo, tanto el hieratismo formulario de los modelos preceptuados para la relación política o administrativa, como, al contrario, la familiaridad forzada por los mismos modelos en el círculo aparentemente más cercano de la relación social son ambos tonos igualmente protocolarios y retóricos. Solo si tenemos un conocimiento profundo de los correspondientes y de las circunstancias de los textos se puede ir un poco más allá a la hora de aislar particularidades propias del texto.

El estudio de sus particularidades formales nos hará pensar casi siempre en lo protocolario o/y la retórica formal por la que se rige. No obstante, algunas de estas particularidades pueden servir para intentar fijar un perfil y calibrar la relación entre dos correspondientes cuyo nombre desconocemos, como es el caso. Indicios verbales internos como el tratamiento son útiles en ocasiones para percibir el tono del escrito y deducir de ahí el estatus y la relación de autor y destinatario.

La primera forma de tratamiento es la de magnífico señor, utilizada en la primera línea del texto, a la cabeza de la introducción (§1) que funge de salutatio, que un manual para la redacción de salutationes y exordios de un escritorio español de la segunda mitad del siglo XV preceptúa para dirigirse a «maestre, duque o marqués». Este uso se puede comprobar, en efecto, en la correspondencia coetánea, como la del conde de Tendilla citada más abajo, en la que este - su secretario, más bien - utiliza este tratamiento para titulados como los mencionados en el manual. La segunda forma es vuestra merced para dirigirse o convocar la atención de su 
correspondiente; las tres ocasiones en las que aparece coinciden en la parte más protocolaria del texto, la introducción (§1). Vos, en cambio, es la variente exclusiva que aparece en la narratio, que constituye el resto de nuestra obrecilla (\$2-§6).

En estudios ${ }^{7}$ sobre la evolución del uso de las dos variantes últimas, se puede apreciar que ya a finales del siglo Xv, vuestra merced se asienta alternando con vos en un mismo documento, saliendo de su original «dominio discursivo "diplomático"», es decir reglamentado en su uso, para convertirse en un «recurso idiomático»8. Así se puede ver también en corpora acotados topográfica y cronológicamente, como, por poner un ejemplo, el producido en una secretaría de, pocos años más o menos, las mismas fechas en las que se compusieron algunos de los textos de la miscelánea. Es el caso del epistolario del conde de Tendilla entre 1504 y 1506, cuyo uso de tratamientos ha estudiado Calderón Campos, quien concluye:

El epistolario muestra con nitidez que vos todavía no se ha desvalorizado excesivamente, al nivel a que llegará en el siglo XVII, pero empieza a perder terreno frente a vuestra merced: lo vemos en la frecuencia con que necesita el refuerzo de señor (vos, señor) y en el hecho de que en las relaciones más formales y distantes predomine vuestra merced. Además, siempre que la relación es claramente asimétrica, de superior a inferior, aparece vos.

De todo el paradigma de vos, es este pronombre el que antes empieza a mostrar síntomas de desvalorización. Los otros miembros de su paradigma, esto es, las formas verbales de segunda persona de plural, el reflexivo os y los posesivos vuestro, -a (estos últimos para evitar la ambigüedad de su 'de él', 'de vuestra merced') acompañan con asiduidad a vuestra merced, por lo que puede afirmarse que acusan más tardíamente que vos la degradación semántica (es decir, en una relación deferente, es posible decir bésoos, señor, las manos o beso las manos de vuestra merced, pero sería descortés tratar a ese mismo interlocutor de vos, sin más) ${ }^{9}$.

$\mathrm{Si}$, aparentemente, el uso en nuestro texto podría ser un testimonio más del desplazamiento de vuestra merced y la convivencia alternativa con vos, el hecho de que en él figure vuestra merced solo en la parte más protocolaria, que vos exclusivamente en la narratio, y que nunca se presente reforzado, podríamos explicárnoslo desde varias pespectivas. En primer lugar, sin salir del marco evolutivo del tratamiento, se podría pensar que nuestra escriptura se presente en un estado anterior a la "idiomatización" y no haya salido totalmente del ámbito reglamentario más habitual en la segunda mitad del siglo XV. En segundo lugar, se podría plantear la posibilidad de dos orígenes distintos de la introducción y del resto del cuerpo de la obra. Aunque también se podría achacar, en tercer lugar, a una estudiada intención autorial, la de mantener, por un lado, la relación formal y, por el otro, reducirla, ora sea por la relación cercana con el destinatario, ora por la propia condición del autor que quiere acentuar su condición de autoridad.

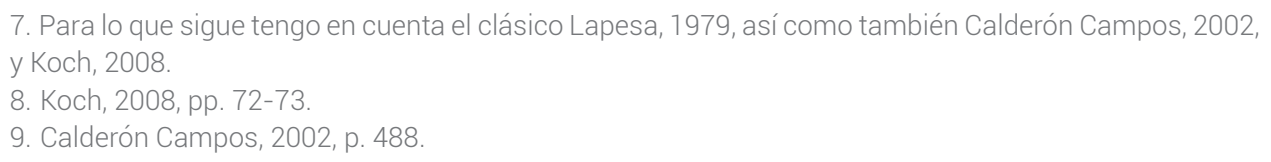


Y es que a esta epístola/oración le podríamos encontrar desde el punto de vista de su doctrina, y a tenor de algún que otro despunte irónico, una cierta disposición a poner al destinatario en la picota. Irónico pareciera, por ejemplo y de un lado, el descarte que el autor hace - ahíto ya de los desgastados argumentos de la devaluada y cansina polémica del siglo $\mathrm{xV}$ - sobre la existencia o no de la fortuna, que el autor ni niega ni afirma (\$2), aunque luego imposte el tono alegórico citándola como causa de la prosperidad del destinatario. La justificación de la puesta en escrito, susceptible, por tanto, de ser publicado, en forma protocolaria de lo que parece -o se finge- haber sido una conversación en la que se trataba el comportamiento censurable del, sin embargo, magnífico señor de estado podríamos explicarla como resultado de una relación entre autoridad moral o magistral y fiel o dependiente, la misma que entre confesores, predicadores o pedagogos y sus sujetos. Pero, si bien la corrección personal forma parte de los discursos de estos, da la sensación de que el del nuestro sobre la gratitud se acompaña de una reticencia sobre el comportamiento del noble, que recuerda mucho el nuevo tono de textos políticos de la inestable segunda mitad del siglo XV, aquellos en que zascas o críticas abiertas e irreverentes -bien distintas de lo que era la tradicional sátira medieval-igualan a rey y súbdito, verbigracia el olim Libro de los pensamientos variables ${ }^{10}$, en el que un villano/autor dialoga de tú a tú sobre el buen gobierno con el joven Rey [Fernando]. Tampoco está de más recordar algunos excesos verbales de Alonso de Palencia para con sus superiores en su obra alegórica, epistolar o historiográfica.

Si el género dialogado se convierte, con evolución formal, adición de una verdadera polifonía semántica y recuperación de sus modelos clásicos menos hieratizados, en privilegiado medio para la difusión de ideas en materias muy divergentes pero de interés moderno, también la epístola se metamorfosea y puede servir para, en el ámbito de la familiaridad clásica, atenuar barreras, escalafones o jerarquías, dotando de autoridad a la voz inferior en la jerarquía social, que en el ámbito literario tout court dará lugar, andando el tiempo, a sustanciosas parodias formales como Lazarillo de Tormes.

Desde el punto de vista político, se percibe ya una superación de los tópicos fosilizados de la sociedad feudal, apuntando al pragmatismo de la acción-reacción, de la que será dechado el mismo monarca que sería el príncipe de Maquievelo y el político de Gracián. Es por ello por lo que en escripturas tan menudas como esta, y en las propias circunstancias de su conservación, podemos documentar actitudes políticas de los nuevos letrados y burócratas en general, o en el desarrollo de conceptos que devendrán caracterizadores de la teoría política de la Edad Moderna.

De entrada, el término gratitud es aún por los años en que esta carta se escribe un neologismo o latinismo especializado, y por eso quizá se destaca en la rúbrica. Como señala un especialista en la terminología política, Galloway, gratitudo parece haber tenido en buena parte de la Edad Media un sentido económico más que medio de configurar una "selfless or self-aggrandizing practice» ${ }^{11}$. Si bien se trata de una noción teológica de alcance en el pensamiento agustiniano, en la escolástica

10. Gómez-Sierra, 2000.

11. Galloway, 1994, p. 367. 
se agranda su sentido especializado como principio para la economía, aunque en el terreno de la moral y de la predicación alcanza una categoría ética que virtualmente lo presenta como la consecuencia contraria de la avaricia. Es a fines de la Edad Media cuando se verifica «tight knitting of such vocabulary and consequently a supercharging of social and ethic meanings» ${ }^{12}$.

En nuestra escriptura/oración/carta es, abiertamente, un concepto político, que ya no se refiere a una relación económica o puramente ética, como era la gratitudo política natural - podría empezar por invocar aquí, si viniera al pelo, la antropología de Marcel Mauss y su teoría del don y, a la zaga de este, la propuesta de LéviStrauss de la sociedad como un sistema de dones y contra-dones, tanto en el terreno económico como social-; o como era también la gratificación feudal, siempre en sentido descendente y no igualitario. Superando acaso la idea de beneficium, que sirve, durante la Edad Media, y a costa de Cicerón y de Séneca, para cargar de sentido político el agradecimiento y definir una de las virtudes del monarca, la liberalitas - por citar implícitamente la obra de Sénea, De beneficiis-, reconoceríamos en gratitud, en tanto que virtud principal que legitima el señorío, un paso más en el camino por el que se va desplazando gratia como concepto político, desde la Edad Media hasta arribar al sentido complejo que tanta importancia tendrá en la Edad Moderna.

La propia presencia del término gratitud o gratitut en los textos españoles podría ser bien significativa. Si consideramos relativamente representativo el CORDE, en su estado actual un tanto desmedrado, podemos comprobar que en romance gratitud o gratitut se documenta en un total de dieciocho ocasiones, la primera en 1428; reaparece en los años cuarenta una sola vez, y habrá que esperar a los ochenta para percibir una verdadera regularidad semántico-política en su uso. Fuera de estas dos primeras apariciones, que no tienen trascendencia política, en la reaparición del término a finales del siglo XV , se puede percibir el cambio semántico e incluso la especialización del término, por lo que no es desdeñable el hecho de que nueve de las dieciséis entradas se hallen en documentos administrativos del ámbito del Estado.

En esta situación intermedia, en nuestro caso, otros conceptos políticos, como el de servicio, se integran bien en esta arqueología de la gracia en la Edad Moderna. La dependencia y obligación mutua e inseparable que implica el servicio, como ha señalado María Asenjo González (1999), y la consiguiente gratitud rompen con las relaciones desiguales entre dador y receptor agradecido de una relación económica o moral. Y, curiosamente, en el último y más importante párrafo de nuestra carta, se dota a la gratitud de una sustancialidad política como instrumento para la creación y organización de Estado con mayúscula y de estado con minúscula, el nobiliario. Utiliza nuestro letrado la metáfora alquímica, en cuya obra nada sobra y 
todo se integra: la gratitud se deja relatar como la depuración metálica, que acentúa una dependencia por medio de un igualamiento. De la imaginería alquímica se sirve, como es bien sabido, la teoría política ${ }^{13}$.

La preferencia o selección desde una perspectiva léxico-literaria de un latinismo, gratitud, enriquecido semánticamente y que se difunde sobre todo en la lengua castellana a partir de los años ochenta del siglo XV, y su destaque en la rúbrica de la nuestra oración, en lugar de los conceptos tradicionales de gradescimiento o agradecimiento, que se mantienen entonces y desde la época alfonsí, es un indicio del quiebro de sentido y de la nueva concepción política.

Además, al insistir el autor del discurso en la adquisición por parte del noble destinatario de una situación superior a la de su casa y nacimiento, podemos interpretarlo también como una defensa de la regularidad de las relaciones de gracia y servicio también en la nobleza, como en la monarquía, algo que vendría a regularizar jurídicamente una relación aleatoria o basada meramente en intereses coyunturales, como sabemos fue hasta hacía pocos decenios en la Castilla de las banderías y de los abusos nobiliarios.

Ningún indicio hay de la identidad de los protagonistas del escrito, el autor y el caballero engrandecido. Si la relación entre este y sus parientes, una suerte de familia que ha colaborado en el ascenso del cabeza o de la persona destacada del linaje a un nivel de grandeza que este nunca tuvo, está en el meollo del origen de la escriptura, no parece tan clara la de los dos protagonistas principales. Alguna familiaridad entre los dos se podría deducir de lo ya dicho, verificado con las pocas pistas que nos dan los tratamientos, que se puede corresponder con un estatuto formal de autoridad por su condición y relación con el destinatario, o con una andadura semántica desde la que el autor, por vía de la familiaridad retórica o real, se eleva al tomar la palabra autorizada colocándose a la altura de su destinatario.

Si nos atamos a los autores representados en el manuscrito misceláneo y resaltamos la vinculación de varios de los textos al círculo cordobés de los Angulo, se podría pensar en la mano de un letrado como Martín Fernández de Angulo, y en un receptor originario de la misma ciudad. La casa de Aguilar aparece en algún otro documento de nuestra miscelánea; a saber si alguno de sus miembros es el destinatario que buscamos. Por ejemplo, Alonso de Aguilar, que en efecto encumbró su casa a lo largo de los años que ostentó el señorío (1455-1501), o, mejor aún, a tenor de la descripción de nuestra scriptura, en el Gran Capitán.

Concluyo. La misma persona que agavilla estos productos funcionariales en el manuscrito citado arrostró también un trabajo ambicioso, el de reunir, como dice en el borrador de uno de los dos prólogos que pretendían antecedieran a su obra, «notables oraçiones y epístolas y otras dulçes hablas propuestas en consejos y en otros convenientes lugares hechas y ordenadas por algunos varones exçellentes,

13. Por poner un ejemplo sin salir de nuestro contexto, el fiel mayordomo de la reina Isabel, Juan Álvarez Gato, al interpretar en términos providencialistas el atentado de Barcelona sostiene que Dios permitió la herida del Rey para dejar bien clara la precedencia que le reconocía, «quel oro fino no lo afinan mucho, syno porque suba a todos los quillates» (Obras completas, p. 186). 
así de los muy antiguos como de los modernos». Una buena parte del trabajo es resultado del vaciado de Tito Livio, Curcio Rufo, las arengas de historia troyana de Guido delle Colonne a partir de la traducción de Fernández de Heredia, discursos de Cicerón, etc., etc., etc., con breves comentarios contextualizadores ${ }^{14}$. Este trabajo nunca pasó de la condición de borrador, y, a día de hoy, se conserva con las particularidades materiales y gráficas propias de las labores realizadas en cancillerías y secretarías, en soportes - verbigracia, cuadernos horadados de papel no muy fino- y según las formas de los materiales de esa procedencia, como algunos códices historiográficos de autor del siglo XV, estudiados por Francisco Bautista (2014) o Inés Fernández-Ordóñez (2012). Es evidente: la recuperación de «arengas, discursos y propusiçiones latinas en lengua romance», labor que se pretendió en los primeros escarceos de un humanismo civilista y de ambición política como el liderado por Enrique de Villena -que es, por cierto, aquel primer usuario documentado de gratitud en lengua castellana al que antes me refería y cuyas son las palabras que acabo de citar-; la recuperación, digo, de estos materiales clásicos destinados a fundirse con los que veíamos en la miscelánea de marras es ya de por sí un buen indicio de la importancia que sus propios actores daban a la argamasa literaria de que se valían en la consolidación de su clase y en sus nuevas relaciones con el poder.

\section{BiBLIOgRAFÍA}

Álvarez Gato, Juan, Obras completas, ed. Jenaro Artiles Rodríguez, Madrid, CIAP, 1928.

Asenjo González, María, «Las ciudades», en Orígenes de la monarquía hispánica: propaganda y legitimación (ca. 1400-1525), dir. José M. Nieto Soria, Madrid, Dykinson, 1999, pp. 105-140.

Bautista, Francisco, «Alvar García de Santa María y la escritura de la historia», en Modelos intelectuales, nuevos textos y nuevos lectores en el siglo XV. Contextos literarios, cortesanos y administrativos, presentación y dir. Pedro M. Cátedra, Salamanca, SEMYR, 2012, pp. 27-59.

Calderón Campos, Miguel, «Fórmulas de tratamiento en las cartas del Conde de Tendilla (1504-1506)», en Actas del V Congreso Internacional de Historia de la Lengua Española, Valencia 31 de enero-4 de febrero 2000, coord. María Teresa Echenique Elizondo y Juan Pedro Sánchez Méndez, Madrid, Gredos, 2002, pp. 477-488. También en Tonos digital. Revista de Estudios Filológicos, 5,2003 , s. p.

Cátedra, Pedro M., «Tratado que hizo Alarcón», alquimista del arzobispo Alonso Carrillo, Salamanca, Seminario de Estudios Medievales y Renacentistas / Sociedad Española de Estudios Medievales y Renacentistas, 2002a.

14. Remito al estudio extenso dedicado a estos materiales en mi libro en prensa. 
Cátedra, Pedro M., «Filología y derecho: subjetividad humanista e identidad política en la obra de Enrique de Villena», en Philologie et subjectivité, ed. de Dominique de Courcelles, Paris, École des Chartes, 2002b, pp. 23-40.

Cátedra, Pedro M., «La literatura funcionarial en tiempos de los Reyes Católicos», en «Siempre soy quien ser solía». Estudios de literatura española medieval en homenaje a Carmen Parrilla, ed. Antonio Chas Aguión y Cleofé Tato García, La Coruña, Servizo de Publicacións da Universidade de A Coruña, 2009a, pp. 57-82.

Cátedra, Pedro M., «Oratoria política y modelo de propaganda. La Oración de Juan Díaz de Alcocer en la proclamación de Isabel la Católica (1474)», Atalaya, 11, 2009b, s. p.

Cátedra, Pedro M., Modelos intelectuales, nuevos textos y nuevos lectores en el siglo XV, II, Literatura funcionarial a finales de la Edad Media. Apuntes y torsos, Salamanca, SEHL / SEMYR, en prensa.

Deyermond, Alan D., «"Sí, ministro". Las prácticas administrativas en la literatura medieval española», en Actas del IX Congreso Internacional de la Asociación Hispánica de Literatura Medieval (A Coruña, 18-22 de septiembre de 2001), ed. Carmen Parrilla, La Coruña, Universidade de A Coruña / Editorial Toxo Soutos, 2005, pp. 127-155.

Fernández-Ordóñez, Inés, Transmisión y metamorfosis. Hacia una tipología de mecanismos evolutivos en los textos medievales, Salamanca, SEMYR, 2012.

Galloway, Andrew, «The Making of a Social Ethic in Late-Medieval England: from Gratitudo to Kyndenesse», Journal of the History of Ideas, 55.3, 1994, pp. 365-383.

Gómez-Bravo, Ana M. ${ }^{a}$, Textual Agency: Writing Culture and Social Networks in Fifteenth-Century Spain, Toronto, University of Toronto Press, 2013.

Gómez-Sierra, Esther, Diálogo entre el prudente rey y el sabio aldeano (olim Libro de los pensamientos variables), Londres, Queen Mary and Westfield College (Department of Hispanic Studies), 2000.

Herter, Fritz, Die Podestaliteratur Italiens im 12. und 13. Jahrhundert, Leipzig, B. G. Teubner, 1910.

Koch, Peter, «Tradiciones discursivas y cambio lingüístico: el ejemplo del tratamiento "vuestra merced" en español», en Sintaxis histórica del español y cambio lingüístico. Nuevas perspectivas desde las tradiciones discursivas, coord. Johannes Kabatek, Madrid / Frankfurt am Main, Iberoamericana / Vervuert, 2008, pp. 53-88.

Lapesa, Rafael, «Personas gramaticales y tratamientos en español», en Homenaje a Menéndez Pidal, IV, Madrid, Universidad de Madrid, 1979, pp. 121-167.

Rábade Obradó, María del Pilar, «El doctor Juan Díaz de Alcocer: apuntes biográficos de un servidor de los Reyes Católicos», Espacio, tiempo y forma. Serie III, Historia medieval, 3, 1990, pp. 259-288. 